\title{
ANTI-INFLAMMATORY ACTIVITY OF TURKEY SOURCE PUMPKIN SEED OIL IN RAT EDEMA MODEL
}

\author{
EMRE ARSLANBAS ${ }^{1 *}$, HAKI KARA ${ }^{2}$, MEHMET ONDER KARAYIGIT ${ }^{3}$ \\ HALEF OKAN DOGAN ${ }^{4}$ and SEYMA NUR YILDIZ ${ }^{4}$
}

\author{
${ }^{1}$ Pharmacology and Toxicology Department, Faculty of Veterinary Medicine, \\ Atatürk University, Erzurum, Turkey \\ ${ }^{2}$ Pharmacology and Toxicology Department, Faculty of Veterinary Medicine, \\ ${ }^{3}$ Pathology Department, Faculty of Veterinary Medicine, \\ ${ }^{4}$ Medicinal Biochemistry Department, Faculty of Medicine, \\ Sivas Cumhuriyet University, Sivas, Turkey
}

\begin{abstract}
This study aimed to determine the effects of Turkey-sourced pumpkin seed oil (PSO), administered orally to rats in different dosages, to research its anti-inflammatory effect in rat edema model, induced by carrageenan, based on different dosages, and to evaluate its effects comparatively with indomethacin. The study was conducted on 42 rats in total, divided into 7 groups (control, carr, PSO40, PSO100, PSO40+carr, PSO100+carr and indo+carr). In the study, doses of 40 and $100 \mathrm{mg} / \mathrm{kg}$ of PSO were found to significantly suppress rat paw edema in time, and it was observed that this effect was more pronounced in the fourth hour. It was found that MDA and cytokine (TNF- $\alpha$, IL-6, IL-1 $\beta$ ) levels were inhibited, and GPX and SOD activities were enhanced in groups that received PSO and indo+carr groups. Histopathological examinations also support these findings. As a result of the study, the significant anti-inflammatory effect of Turkey-sourced PSO was attributed to the existence of unsaturated fatty acids and enriched phytochemical compounds.
\end{abstract}

Keywords: pumpkin seed oil, carrageenan, anti-inflammatory, edema model, indomethacin, rat

Since treatment of inflammation with analgesic, nonsteroidal anti-inflammatory drugs (NSAID) and corticosteroids causes undesired side effects, such as heightened sensitivity to infection, rapid rise in the frequency of Diabetes mellitus, muscle weakness, hypersensitivity reactions, stomach disorders, and gastric erosion, and analgesic abuse symptoms, people have started to look for alternative treatments for inflammation (1). The studies also showed that naturally bioactive compounds, extracts and oils derived from vegetables, fruits, oily seeds, and medical herbs have the potential to promote robust health thanks to their useful anti-inflammatory properties, and they can be effective against various diseases (2).

Pumpkin seeds (PSs) are rich in oil and, despite various genetic variances, the oil content of seeds varies between $42 \%$ and $54 \%(3,4)$. PSO is an edible natural product that rich in many different antioxidants and food supplements, such as unsaturated fatty acids, vitamins, carotenoids, tocopherols, phytosterols, phenolic compounds, essential fatty acids, hydrocarbon, choline, squalene, triterpenoids, and selenium (Se) (5-7). PSO is mainly cultivated in South and East Austria and its neighboring countries, North America and the southern regions of Central America, and certain regions in Africa and Southern China $(6,8,9)$. It is widely used for high blood pressure, atherosclerosis, benign prostatic hyperplasia, urinary bladder disorders, and worm and tapeworm cases among the public $(7,10,11)$. It was accentuated in the studies that PSO has antitumoral, antihypertensive, antiasthmatic, antibacterial and antidiabetic activity and useful effects in benign prostatic hyperplasia. It was also emphasized that it strengthens the memory, reduces cholesterol, reinforces the development of the human brain, and slows down cardiovascular and cerebrovascular diseases and obesity $(4,12-14)$.

Carrageenan induction, an inflammation model, is used to evaluate the contribution of natural products in resistance to biochemical changes, 
which are mostly associated with acute inflammation $(1,15)$. This study aimed to determine the effects of Turkey-sourced PSO, administered orally to rats in different dosages, to research its antiinflammatory effect in rat edema model, induced by carrageenan, based on different dosages, and to evaluate its effects comparatively with indomethacin.

\section{EXPERIMENTAL}

\section{Chemical reagents and drugs}

Carrageenan and indomethacin and the agents used for diagnostic purposes were obtained from Sigma-Aldrich Chemical Co. (St. Louis, Missouri, USA). PSO was obtained from Kirıntı Baharat (Kocaeli, Turkey). Commercial kits used for the determination of glutathione peroxidase (GPX), superoxide dismutase (SOD), tumor necrosis factoralpha (TNF- $\alpha$ ), interleukin $1 \beta$ (IL-1 $\beta$ ) and interleukin 6 (IL-6) were purchased from Fine Biotech Co (Fn-Test, China). The purity of all chemical reagents was at least analytical grade.

\section{Experimental protocol}

This study was conducted with 42 rats of the Wistar albino species. They were 4-month adult males. All experiments were performed in Sivas Cumhuriyet University. The rats were kept under standard experimental animal laboratory conditions (12 h of light/dark cycle, $24 \pm 2^{\circ} \mathrm{C}, 35-60 \%$ humidity) and food and water were given ad libitum. Experiments were carried out in accordance with the Guide for the Care and Use of Laboratory Animals (a publication by DHEW (NIH) 8523, 1985). The study was conducted upon obtaining a permit (date: 01/06/2017, issue: 65202830-050.04.04-68) from the Local Ethics Committee for Animal Experiments at Sivas Cumhuriyet University (Turkey).

The experimental animals were divided into 7 groups ( $\mathrm{n}=6$ in each group): control, carr, PSO40, PSO100, PSO40+carr, PSO100+carr and indo+carr. Carrageenan was dissolved in $1 \%$ sterile saline and a $0.1 \mathrm{ml}$ dosage was administered subcutaneously under the right rear paw one hour after the last corn oil, PSO40 or PSO100 application. Turkey-sourced PSO was administered to the rats in the PSO40 and PSO100 groups, and in the PSO40+carr and PSO100+carr groups, by gavage at 40 and 100 $\mathrm{mg} / \mathrm{kg}$ bw/day for 4 weeks, and the PSO40+carr and PSO100+carr groups were given carrageenan subcutaneously one hour after the last PSO40 or PSO100 administration. Indomethacin was applied at a dosage of $10 \mathrm{mg} / \mathrm{kg}$ bw/day through gavage, and carrageenan was administered subcutaneously one hour after the application. The control and carr rats received corn oil through gavage for 4 weeks, and the carr group was administered carrageenan subcutaneously one hour after the last corn oil application. Administrations were made to all groups in accordance with the experimental protocol prepared according to Zuhair et al. (16).

According to the results of the analysis conducted by the firm, the fatty acid composition of the PSO used in the study was reported as $50.89 \%$ linoleic acid, $31.01 \%$ oleic acid, $10.81 \%$ palmitic acid, $5.52 \%$ stearic acid, $1.30 \%$ linolenic acid, $0.45 \%$ lignoceric acid, $0.20 \%$ arachidic acid, $0.11 \%$ ecocenoic acid and $0.10 \%$ myrystic acid. Paw volume and size of edema were measured by planimeter in all application groups before and after administering carrageenan. These measures were repeated in the 1st, 2nd, 3rd and 4th h after administering carrageenan, and the results were comparatively evaluated (15). Any change in paw volume was taken as a comparison criterion against paw line measurement, and the percentage of edema inhibition was calculated as follows: Inhibition percentage $=[1-$ $\left.\left(\mathrm{V}_{\mathrm{U}} / \mathrm{V}_{0}\right)\right] \times 100$. $\left[\mathrm{V}_{\mathrm{U}}\right.$ : means volume of the right rear paw of the rat in the administration group; $\mathrm{V}_{0}$ : means volume of the right rear paw of the rat in the carrageenan group].

The degree of inflammation was calculated according to the following formula and was evaluated as a percentage of inflammation: Percentage of inflammation $=\left(\mathrm{P}_{\mathrm{U}}-\mathrm{P}_{0}\right) / \mathrm{P}_{0} \times 100 .\left[\mathrm{P}_{\mathrm{U}}\right.$ : means volume of the right rear paw of the rat after carrageenan is administered; $\mathrm{P}_{0}$ : means volume of the right rear paw of the rat before carrageenan is administered] (1).

When the administrations were ended, blood samples were taken from the rats' hearts under anesthetic. The blood samples were centrifuged at 3000 $\mathrm{rpm}$ for $15 \mathrm{~min}$, and sera were kept at $-80^{\circ} \mathrm{C}$ until further analyses. Then tissue samples (liver, kidneys) were removed carefully through necropsy, and, while some of these samples were kept within $10 \%$ formaldehyde solution for histopathological examination, the remainder were kept at $-80^{\circ} \mathrm{C}$ for other analyses.

Lipid peroxidation was determined as malondialdehyde (MDA) according to the method applied by Ohkawa et al. (17). MDA analyses were conducted on rat serum and tissue samples. The determined absorbance value was calculated as $\mathrm{nmol} / \mathrm{ml}$ from the standard curve of MDA. The samples were read against the blind at $532 \mathrm{~nm}$ wavelength in a 
spectrophotometer device (Perkin Elmer, Lambda 25 UV/VIS, USA).

TNF- $\alpha$, IL-1 $\beta$ and IL-6 levels, GPX and SOD enzyme activity were found in accordance with the procedure recommended by the manufacturer, using a standard enzymatic kit. Absorbance was read at $450 \mathrm{~nm}$ using an ELISA reader (Thermo Multiscan Go, USA).

\section{Histopathological analysis}

Rat liver and kidney tissue samples, which were kept in $10 \%$ formaldehyde solution for histopathological examinations, were immersed in paraffin and blocked after washing in tap water overnight, and alcohol-xylol series were applied. Then, sections of $5 \mu \mathrm{m}$ paraffin blocks were placed on glass slides for hematoxylon-eosin staining after undergoing the alcohol-xylol series. The entire surface of each cross-section of liver and kidney tissues of the stained application groups was examined. Histopathological evaluation was conducted by examining the entire cross-section of each organ semi-quantitatively. Each organ cross-section, taken from each rat, was analyzed under a light micro-

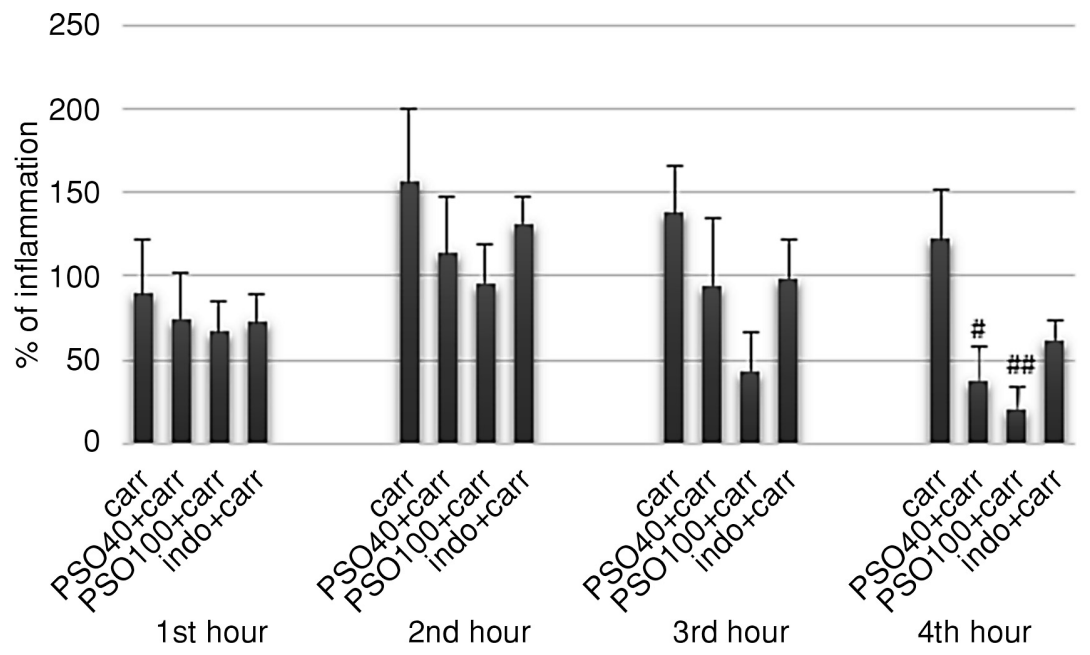

\#, \#\# Statistically meaningful when compared with carr group $(\# \mathrm{P}<0.05$, \#\# $\mathrm{P}<0.01$ )

Figure 1. Inflammation percentage levels of experimental groups on the 1st, 2 nd, 3 rd and 4 th hour.

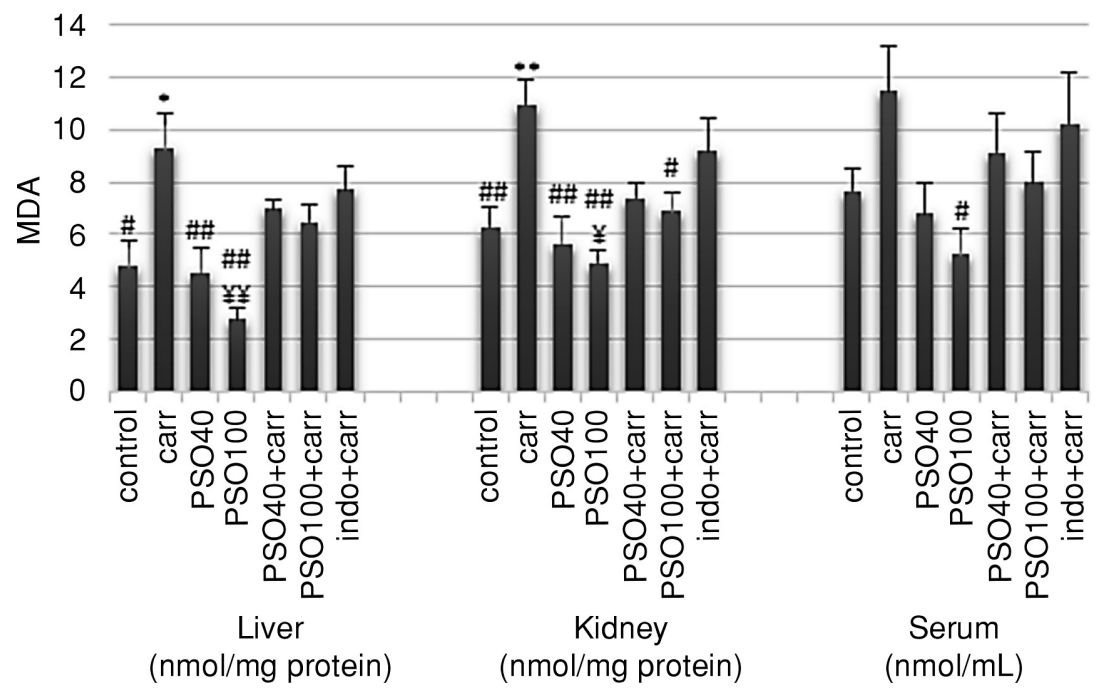

$*$, ** Statistically meaningful when compared with control group $(* \mathrm{P} 0.05, * * \mathrm{P}<0.01)$

\#, \#\# Statistically meaningful when compared with carr group $(\# \mathrm{P}<0.05$, \#\# $\mathrm{P}<0.01$ )

$¥$, ¥ Statistically meaningful when compared with indo+carr group ( $¥ \mathrm{P}<0.05$, ¥¥ $\mathrm{P}<0.01$ )

Figure 2. Liver, kidney and serum MDA levels of experimental groups. 
scope (Zeiss AxioCam ERc5s, Germany) for inflammation, hyperemia, edema/protein leak in tubules, fibrosis, necrosis, bleeding and degeneration, and the magnitude of any changes was rated to reach a final score.

\section{Statistical analyses}

The data were analyzed with SPSS (Version 23) software. The results were calculated as the mean and standard error of the mean (SEM), and it was determined by Kolmogorov-Smirnov whether the data were distributed normally or not. One-way variance analysis (One-way ANOVA) and post hoc analysis Tukey test were used to determine the dif- ference between groups. The level of statistical significance was accepted as $\mathrm{P}<0.05$.

\section{RESULTS}

Anti-inflammatory activity, oxidation and cytokine parameter results

Edema has occurred in the right rear paw of rats in experimental groups (control, PSO40 and PSO100 groups except) to which carrageenan was administered in this study, in which the rat edema experiment model was successfully established. It was found that doses of 40 and $100 \mathrm{mg} / \mathrm{kg}$ of PSO significantly suppress rat paw edema in time, and

Table 1. Scoring of histopathological properties of cross-sections of liver tissue samples of experimental groups.

\begin{tabular}{|l|c|c|c|c|c|c|c|}
\hline \multirow{2}{*}{ Groups } & \multicolumn{5}{c|}{ Histopathological properties } \\
\cline { 2 - 7 } & Inflammation & Hyperemia & Edema & Fibrosis & Necrosis & Bleeding & Degeneration \\
\hline Control group & - & - & - & - & - & - & - \\
\hline Carr group & ++ & ++ & - & - & - & + & + \\
\hline PSO40 group & - & + & - & - & - & - & - \\
\hline PSO100 group & - & - & - & - & - & - & - \\
\hline PSO40+carr group & + & + & - & - & - & + & - \\
\hline PSO100+carr group & - & + & - & - & - & + & - \\
\hline Indo+carr group & ++ & + & - & - & - & + \\
\hline
\end{tabular}

$*_{-}$, none; +, slightly severe; ++, mid-severe

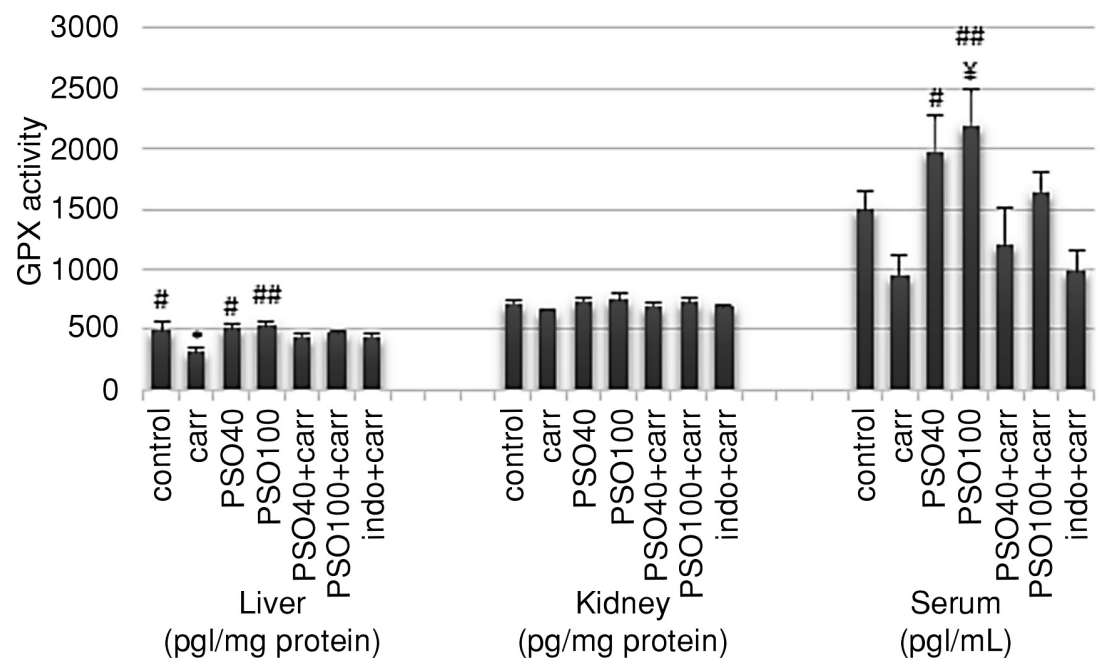

* Statistically meaningful when compared with control group $(\mathrm{P}<0.05)$

\#, \#\# Statistically meaningful when compared with carr group $(\# \mathrm{P}<0.05$, \#\# $\mathrm{P}<0.01$ )

$¥$ Statistically meaningful when compared with indo+carr group $(\mathrm{P}<0.05)$

Figure 3. Liver, kidney and serum GPX levels of experimental groups. 


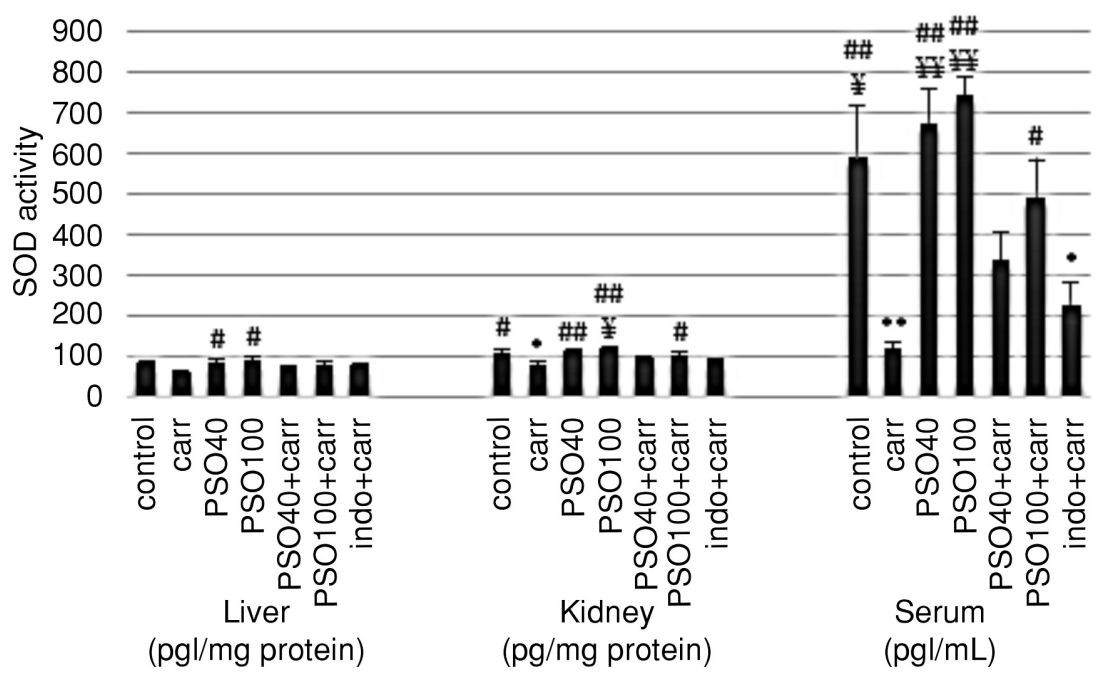

$*$, ** Statistically meaningful when compared with control group $(* \mathrm{P}<0.05$, ** $\mathrm{P}<0.01)$

\#, \#\# Statistically meaningful when compared with carr group (\# $\mathrm{P}<0.05$, \#\# $\mathrm{P}<0.01$ )

$¥$, ¥¥ Statistically meaningful when compared with indo+carr group $(¥ \mathrm{P}<0.05$, ¥¥ $\mathrm{P}<0.01$ )

Figure 4. Liver, kidney and serum SOD levels of experimental groups.

Table 2. Scoring of histopathological properties of cross-sections of kidney tissue samples of experimental groups.

\begin{tabular}{|l|c|c|c|c|c|c|c|}
\hline \multirow{2}{*}{ Groups } & \multicolumn{5}{|c|}{ Histopathological properties } & \multirow{2}{*}{ Protein } \\
\cline { 2 - 7 } & Inflammation & Hyperemia & $\begin{array}{c}\text { leak in } \\
\text { tubules }\end{array}$ & Fibrosis & Necrosis & Bleeding & Degeneration \\
\hline Control group & - & - & - & - & - & - & - \\
\hline Carr group & + & ++ & - & - & - & - & - \\
\hline PSO40 group & - & - & - & - & - & - \\
\hline PSO100 group & - & - & - & - & - & - & - \\
\hline PSO40+carr group & - & + & - & - & - & - & - \\
\hline PSO100+carr group & - & - & - & - & - & - & - \\
\hline Indo+carr group & - & ++ & - & - & - & - & - \\
\hline
\end{tabular}

* -, none; +, slightly severe; ++, mid-severe

the maximum inhibition percentage of edema volume was observed $4 \mathrm{~h}$ later. In addition, administering PSO in doses of 40 and $100 \mathrm{mg} / \mathrm{kg}$ was found to significantly reduce the inflammation percentage in the fourth hour $(\mathrm{P}<0.05, \mathrm{P}<0.01)$. In the fourth hour, inflammation percentages and inhibition percentages were $37.45 \%$ and $44.71 \%$ in the PSO40+carr group, $20.19 \%$ and $50.28 \%$ in the PSO100+carr group, and $61.89 \%$ and $29.27 \%$ in the indo+carr group respectively (Fig. 1).

Serum MDA levels were found to be significantly reduced by the administration of PSO in doses of $100 \mathrm{mg} / \mathrm{kg}$ of PSO $(\mathrm{P}<0.05)$ (Fig. 2). Liver and serum GPX levels were observed to rise meaningfully in doses of 40 and $100 \mathrm{mg} / \mathrm{kg}$ of PSO $(\mathrm{P}<$ $0.05, \mathrm{P}<0.01$ ) (Fig. 3). It was found that liver and kidney SOD levels were significantly boosted by the administration of PSO of 40 and $100 \mathrm{mg} / \mathrm{kg}(\mathrm{P}<$ 0.05, P < 0.01). (Fig. 4).

In addition, serum IL- $1 \beta$ and TNF- $\alpha$ levels were observed to be meaningfully suppressed by the administration of PSO at 40 and $100 \mathrm{mg} / \mathrm{kg}$ doses (P $<0.01)$. Serum IL-6 levels were found to be significantly inhibited by the administration of PSO in doses of $100 \mathrm{mg} / \mathrm{kg}(\mathrm{P}<0.05)$ (Fig. 5).

\section{Histopathologic results}

The entire surface of cross-sections taken from liver and kidney tissue samples of experimental groups were evaluated for inflammation, hyperemia, edema/protein leak in tubules, fibrosis, necrosis, bleeding and degeneration, and histopathologic 


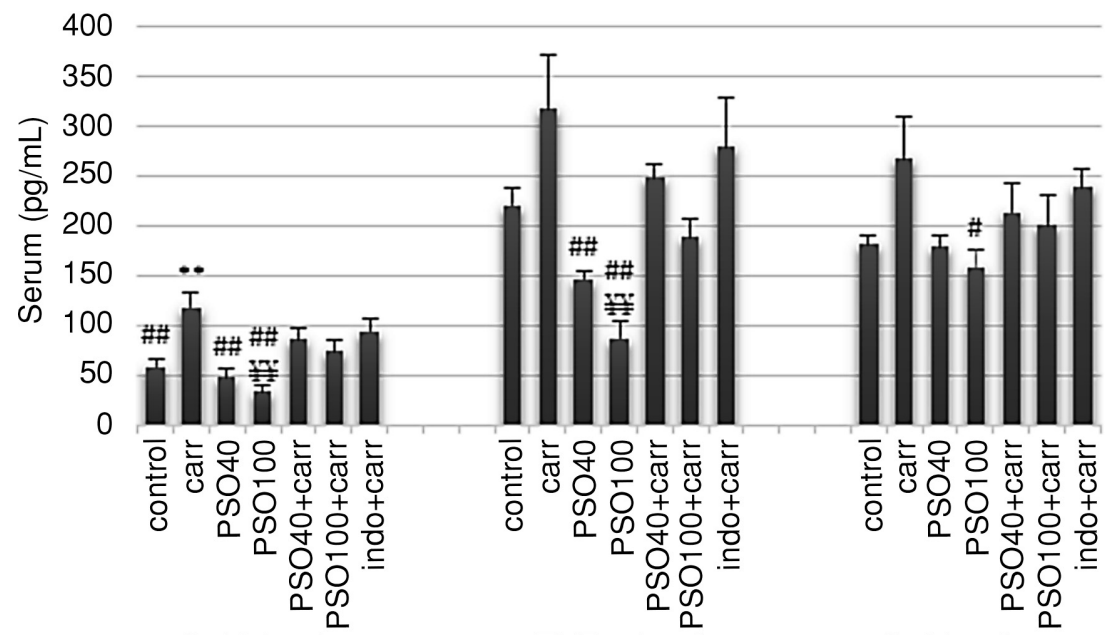

IL-1 $\beta$ levels

TNF- $\alpha$ levels

IL-6 levels

** Statistically meaningful when compared with control group $(\mathrm{P}<0.01)$

\#, \#\# Statistically meaningful when compared with carr group $(\# \mathrm{P}<0.05$, \#\# $\mathrm{P}<0.01)$

¥ Statistically meaningful when compared with indo+carr group $(\mathrm{P}<0.01)$

Figure 5. Serum IL-1 $\beta$ levels, TNF- $\alpha$ levels and IL-6 levels of experimental groups.

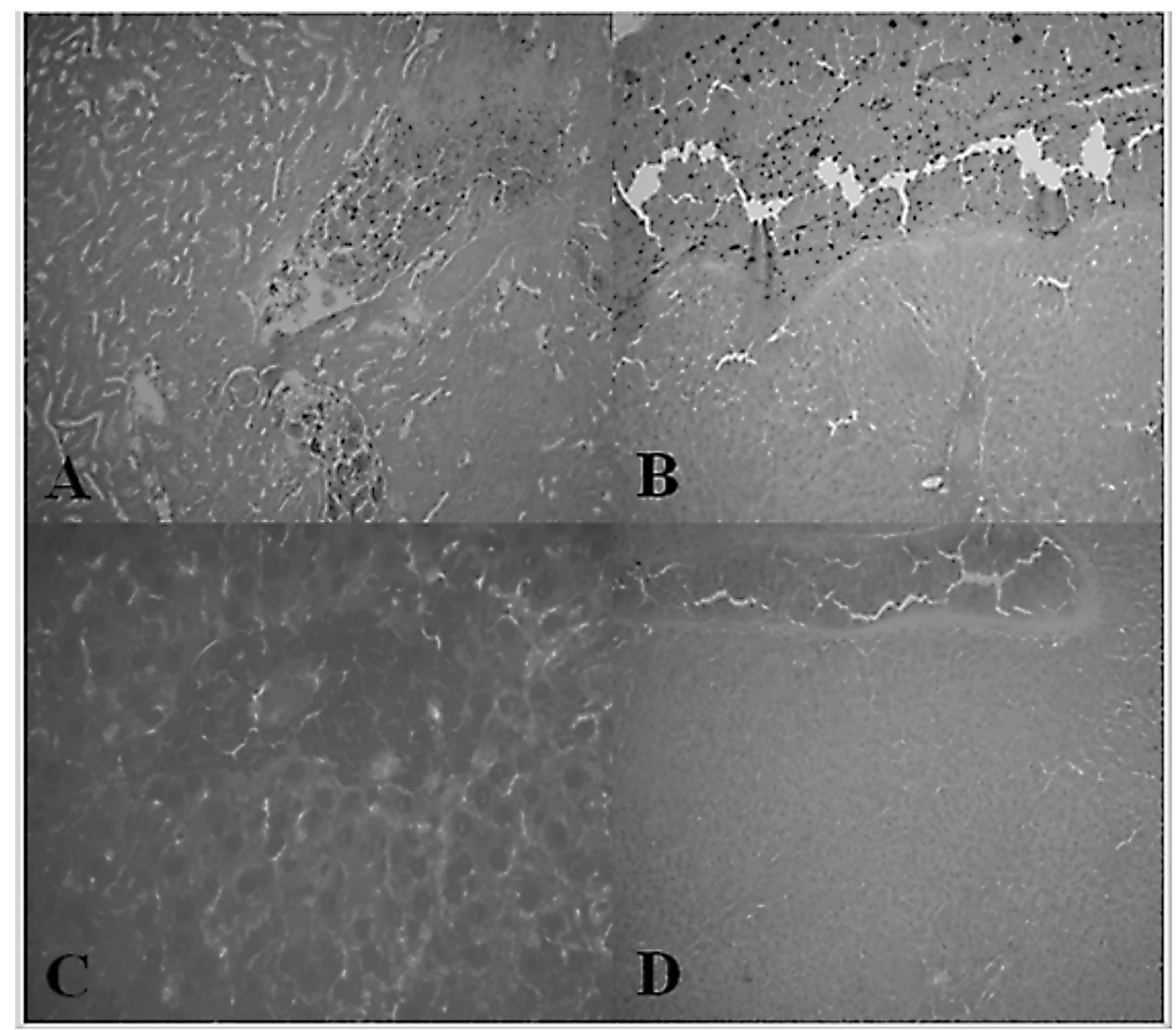

Figure 6. Photos of histopathological stainin. A. Slightly and mildly severe hyperemia in cross-sections of kidney tissue samples. B. Slightly bleeding lesions in cross-sections of liver tissue samples. C. From slightly to mildly severe inflammation findings in cross-sections of liver tissue samples. D. From slightly to mildly severe hyperemia in cross-sections of liver tissue samples. 
changes were scored and summarized in Table 1 and Table 2. No histopathologic change was found in cross-sections taken from liver and kidney tissue samples from the control group. While slightly severe bleeding lesions were found in liver tissue samples from the carr, PSO40+carr, PSO100+carr and indo+carr groups, inflammation ranging from slightly severe to mildly severe, was observed in the carr, PSO40+carr and indo+carr groups. Hyperemia ranging from slight to mild severity was observed in kidney tissue samples from the carr, PSO40+carr and indo+carr groups (Fig. 6).

\section{DISCUSSION AND CONCLUSION}

Phytochemicals have become an area of interest in recent years, particularly for the treatment and prevention of chronic diseases (18).

Injection of carrageenan causes a biphasic event within the inflammation mechanism. Proinflammatory cytokines, such as TNF- $\alpha$, IL-6 and IL-1 $\beta$, histamine and serotonin, are the inflammation mediators that are released within the first hour of the vascular phase (first phase). Prostaglandins are involved in the cellular phase (second phase). These mediators are responsible for rashes, edema and secretions $(1,15)$. In this study, the carrageenaninduced rat edema model was successfully constructed, which is compatible with previous studies $(1,2,15,19,20)$. The injection of carrageenan into the rear paw of rats increased vascular permeability and/or blood flow, which caused growth in the size of edema in all application groups, and initiated the vascular phase of the inflammation mechanism. The inflammation continued, becoming more intensified and reaching its peak in the second hour. The results showed that Turkey-sourced PSO (40 and 100 $\mathrm{mg} / \mathrm{kg}$ doses) caused a significant inhibition in rat paw edema in time. This condition asserts that PSO bears an antagonistic effect against all inflammation mediators in the vascular and cellular phases. It was found that doses of 40 and $100 \mathrm{mg} / \mathrm{kg}$ of PSO significantly reduce the percentage of inflammation in the fourth hour $(\mathrm{P}<0.05)$ (Fig. 1). Furthermore, the maximum inhibition percentage of edema volume was observed in the fourth hour in animals to which PSO was administered in doses of 40 and 100 $\mathrm{mg} / \mathrm{kg}$. It was thought that this may be the maximum inhibition action of PSO on the cyclooxygenase enzyme, which is responsible for the synthesis of prostaglandin. Al-Okbi et al. (21) conducted a study evaluating the anti-inflammatory activities of Egyptian and European varieties of PSO in a rat adjuvant arthritis model. In that study, the inflammation inhibition of the Egyptian and European varieties of PSO in low and high dose applications (40 and $500 \mathrm{mg} / \mathrm{kg}$ respectively) was found to be $31 \%$ and $44 \%, 50 \%$ and $46 \%$, and was consistent with the results of this study (inhibition percentage PSO40+carr group 44.71\%, PSO100+carr group $50.28 \%$ ). Furthermore, it was reported that the low dose of the European variety of PSO reduced MDA the most (-47\%), while the high dose of the Egyptian variety of PSO inhibited TNF- $\alpha$ the most (-31\%). It was found that the results of this study were consistent with TNF- $\alpha$ results. In this study, it was found that MDA and cytokine (TNF- $\alpha$, IL- 6 and IL-1 $\beta$ ) levels were suppressed, and GPX and SOD activities were heightened in groups that received Turkeysourced PSO (PSO40, PSO100, PSO40+carr, PSO100+carr), and indo+carr groups (Figure 2-5). Histopathologic analyses supported these findings (Table 1-2, Fig. 6). The data obtained in this study was found to be compatible with the results of previous studies in terms of anti-inflammatory effect in the rat edema model induced by carrageenan, oxidative stress and immune parameters $(1,20)$, and histopathological changes (2).

As a result of this study, a significant antiinflammatory effect was found, particularly in the group to which a high dosage of Turkey-sourced PSO (100 mg/kg) was administered, and no biogenic effect was observed. This effect was attributed to the existence of rich phytochemical compounds, such as unsaturated fatty acids (mostly linoleic acid and oleic acid), tocopherols, phenolic compounds, phytosterols and $\beta$ carotene within the composition of Turkey-sourced PSO and it was thought that PSO cleanses free radicals, stimulates the activities of antioxidant enzymes, and inhibits the lipid peroxidation mechanism, which occurs as a result of the generation of prostaglandins, the physiological mediators of inflammation.

\section{Acknowledgments}

This work is supported by the Scientific Research Project Fund of Sivas Cumhuriyet University under project number V-064 (CÜBAP, Sivas, Turkey).

\section{Conflict of interest}

All authors declare that they have no conflict of interests. 


\section{REFERENCES}

1. Ben Khedir S., Mzid M., Bardaa S., Moalla D., Sahnoun Z., et al.: Evid. Based Complement. Alternat. Med. 6108203, 12 pages (2016).

2. Ibrahim F.M., Attia H.N., Maklad Y.A.A., Ahmed K.A., Ramadan M.F.: Pharm. Biol. 55, 740 (2017).

3. Eraslan G., Kanbur M., Aslan O., Karabacak M.: Environ. Toxicol. 28, 681 (2013).

4. Procida G., Stancher B., Cateni F., Zacchigna M.: J. Sci. Food Agric. 93, 1035 (2013).

5. Zuhair H.A., Abd El-Fattah A.A., Abd El Latif H.A.: Pharmacol. Res. 35, 403 (1997).

6. Lankmayr E., Mocak J., Serdt K., Balla B., Wenzl T. et al.: J. Biochem. Biophys. Methods 61, 95 (2004).

7. Al-Okbi S.Y., Mohamed D.A., Kandil E., Ahmed E.K., Mohammed S.E.: Grasas Aceites 65, e007 (2014).

8. Butinar B., Bučar-Miklavčič M., Valenčič V., Raspor P.: J. Agric. Food Chem. 58, 5227 (2010).

9. Aliu S., Rusinovci I., Salihu S., Fetahu S., Kika A. et al.: J. Food. Agri. Environ. 14, 28 (2016).

10. Younis Y.M.H., Ghirmay S., Al-Shihry S.S.: Phytochemistry 54, 71 (2000).
11. El-Mosallamy A.E., Sleem A.A., Abdel-Salam O.M., Shaffie N., Kenawy S.A.: J. Med. Food 15, 180 (2012).

12. Adams G.G., Imran S., Wang S., Mohammad A., Kok M.S. et al.: Food Chem. 134, 1919 (2012).

13. Bardaa S., Moalla D., Ben Khedir S., Rebai T., Sahnoun Z.: Pharm. Biol. 54, 581 (2016).

14. Zhao X.J., Chen Y.L., Fu B., Zhang W., Liu Z. et al.: J. Sci. Food Agric. 97, 1158 (2017). doi: 10.1002/jsfa.7842.

15. Azab S.S., Abdel Jaleel G.A., Eldahshan O.A.: Pharm. Biol. 55, 1654 (2017).

16. Zuhair H.A., Abd El-Fattah A.A., El-Sayed M.I.: Pharmacol. Res. 41, 555 (2000).

17. Ohkawa H., Ohishi N., Yagi K.: Anal. Biochem. 95, 351 (1979).

18. Veronezi C.M., Jorge N.: J. Food Sci. 77, 653 (2012).

19. Nkeh-Chungag B.N., Temdie J.R., SewaniRusike C., Fodjo Y.M., Mbafor J.T. et al.: J. Med. Plant. Res. 3, 635 (2009).

20. Ibrahim A.Y., El-Gengaihi S.E., Motawea H.M., Sleem A.M.: Not. Sci. Biol. 3, 22 (2011).

21. Al-Okbi S.Y., Mohamed D.A., Kandil E., AboZeid M.A., Mohammed S.E. et al.: Grasas Aceites 68, e180 (2017).

(C) 2020 by Polish Pharmaceutical Society. This is an open-access article under the CC BY NC license (c) (i) (9) (http://creativecommons.org/licenses/by-nc/4.0/). 